\title{
INFLUÊNCIA DA CASCA DE AMENDOIM COMO COBERTURA VEGETAL PARA A PRODUÇÃO DE ALFACE
}

Luis Eduardo Vieira Pinto ${ }^{1}$, Lucas Faria Nigre ${ }^{2}$, Thadeu Henrique Novais Spósito ${ }^{3}$, Angela Madalena Marchizelli Godinho ${ }^{1}$, Fernando Bernardo Martins ${ }^{1}$

'Universidade do Oeste Paulista - UNOESTE, Programa de Pós-Graduação em Agronomia, Presidente Prudente, SP. ${ }^{2}$ Faculdade de Tecnologia de Presidente Prudente - FATEC, Tecnologia em Agronegócio, Presidente Prudente, SP. ${ }^{3}$ Universidade Estadual Paulista - UNESP, FEIS/ Programa de Pós-Graduação em Agronomia, Ilha Solteira, SP. E-mail: levp@unoeste.br

\section{RESUMO}

O uso de cobertura vegetal no cultivo de hortaliças é uma técnica muito difundida entre produtores agrícolas, pois possui vários benefícios para o solo e planta. O trabalho foi conduzido na Faculdade de Tecnologia de Presidente Prudente, com o objetivo de avaliar a influência da cobertura vegetal aplicada em duas variedades de alface em diferentes concentrações (volume). $O$ experimento foi conduzido em canteiros adotando um delineamento fatorial $(1 \times 2 \times 4)$, sendo a cobertura vegetal (casca de amendoim), duas variedades de alface lisa (Babá de verão) e crespa (Vera) e quatro concentrações de cobertura (testemunha "sem aplicação", 30 litros, 60 litros, 90 litros de casca de amendoim). Foi utilizado o programa Assistat para realização da análise estatística. Para análise de variância foi utilizado o teste F e Tukey (5\%) para comparação das médias. $\mathrm{O}$ uso de 30 litros de casca de amendoim como fonte de cobertura vegetal promoveu o melhor desenvolvimento da alface.

Palavras-chave: Agronegócio. Agroecologia. Umidade. Hortaliças. Arachis hypogaea L.

\section{INFLUENCE OF COVERAGE LIKE PEANUT PLANT BARK FOR LETTUCE PRODUCTION}

\begin{abstract}
The use of vegetation in the cultivation of vegetables is a technique widespread among farmers because it has several benefits for the soil and plant. The work was conducted in Presidente Prudente Technology College, in order to evaluate the influence of vegetation applied in two varieties of lettuce in different concentrations (volume). The experiment was conducted in beds by adopting a factorial design $(1 \times 2 \times 4)$ and vegetation cover (peanut shells), two varieties of plain lettuce (summer Nanny) and curly (Vera) and four coverage levels (control "no application" 30 liters 60 liters 90 liters of peanut shell). It used the Assistat program for statistical analysis. For analysis of variance was used the F and Tukey test (5\%) to compare means. The use of 30 liters of peanut shell as vegetation cover supply promoted the best development of lettuce.
\end{abstract}

Keywords: Agribusiness. Agroecology. Humidity. Vegetables. Arachis hypogaea L. 


\section{INTRODUÇÃO}

Atualmente o consumo de hortaliças tem aumentado devido a maior conscientização da população em busca de uma dieta alimentar mais rica e saudável. Desse modo, o desenvolvimento de sistemas de cultivo com hortaliças, com vistas à otimização da produtividade, tem exigido dos agricultores esforços no sentido de reduzir ou até mesmo eliminar as deficiências do setor produtivo (MONTEZANO e PEIL, 2006).

As hortaliças são importantes componentes de uma dieta saudável e seu consumo em quantidade adequada pode reduzir o risco de doenças cardiovasculares e alguns tipos de câncer (LOCK et al. 2005). As hortaliças são alimentos importantes, pois são fontes de micronutrientes, fibras e de outros componentes com propriedades funcionais, são alimentos de baixa densidade energética, isto é, com poucas calorias em relação ao volume da alimentação consumida, o que favorece a manutenção do peso corporal saudável (VAN DUYN e PIVONKA, 2000).

A alface é uma planta é herbácea, delicada, com caule diminuto, ao qual se prendem as folhas. Estas são amplas e crescem em roseta, em volta do caule, podendo ser lisas ou crespas, formando ou não uma cabeça, com coloração em vários tons de verde, ou roxa, conforme a cultivar, e são essas características que determinam à preferência do consumidor (FILGUEIRA, 2003). O solo ideal para o cultivo dessa hortaliça é o de textura média, rico em matéria orgânica e com boa disponibilidade de nutrientes. Para se obter maior produtividade, é necessário o uso de insumos que melhorem as condições físicas, químicas e biológicas do solo. As maiores produções podem ser obtidas a partir da melhoria das características químicas e físico-química do solo, o que pode ser obtida com o acréscimo de doses crescentes de compostos orgânicos (SOUZA et al., 2005).

Tradicionalmente, a alface é adaptada a condições de temperaturas amenas, com maior produção nas épocas mais frias do ano (MOMENTÉ et al., 2007). Para Feltrin et al. (2005) melhoramentos genéticos, pesquisas e cultivo em ambientes protegido possibilitaram o seu cultivo em todas as épocas do ano. Dentre as diversas variedades cultivadas no Brasil, as mais consumidas são: alface crespa representa $70 \%$ do mercado, seguida da alface americana com $15 \%$, lisa com $10 \%$ e outras como mimosa, vermelha e romana com 5\% (SALA et al., 2008).

Nas últimas décadas, diversas técnicas foram incorporadas ao cultivo de hortaliças. Dessas técnicas, destaca-se a cobertura morta ou "mulching" que é a prática pela qual se aplica, ao solo, material orgânico ou inorgânico como cobertura de superfície (SOUZA e RESENDE, 2003). Dentre as vantagens decorrentes de sua utilização podem ser destacadas, quanto aos atributos do solo, a melhoria da estrutura, a prevenção à erosão e o aporte de matéria orgânica e nutrientes. Além destes atributos, o potencial de controle de ervas espontâneas tem sido também registrado (MACLEAN et al., 2003).

Além disso, a cobertura retém água no solo mantendo-o mais tempo úmido e, assim, é possível aumentar os intervalos entre irrigações. Atua também, como agente isolante, impedindo oscilações bruscas da temperatura do solo e contribuindo para a menor evaporação da água armazenada com melhor aproveitamento do conteúdo de água no solo pelas plantas (BIZARI et al., 2009).

A utilização de cobertura além do controle da temperatura e evaporação da água, promove maior incorporação de matéria orgânica no solo, pois a cobertura depositada na superfície do solo serve como reserva de nutrientes, onde a disponibilização pode ser rápida e intensa ou lenta, de acordo com a espécie utilizada, quantidade de fitomassa presente, condições ambientais e atividade dos macro e microrganismos (OLIVEIRA et al., 2006; ROSOLEM et al., 2003).

De acordo com Souza e Resende (2003), por meio da cobertura do solo, ocorre influência positiva nas qualidades físicas, químicas e biológicas do solo, bem como a diminuição da erosão, criando condições ótimas para o crescimento radicular. 
No Brasil, mesmo com os avanços nos estudos de reaproveitamento dos resíduos agroindustriais, a biomassa residual de atividades agrícolas ainda é pouco aproveitada, sendo muitas vezes descartada para decomposição natural, gerando alguns passivos ambientais como a geração de gás carbônico e metano (DIAS et al, 2012). Nesse contexto, a produção de diferentes carvões ativados, utilizando-se resíduos (cascas de amendoim), consiste numa alternativa interessante para obter materiais com elevada área superficial para serem usados em diversas aplicações (SANTIAGO et al., 2005).

Além disso, o aproveitamento deste resíduo contribui com a reposição dos nutrientes retirados pelas plantas durante seu ciclo, além de conferir ao solo uma melhor agregação de suas partículas, melhor capacidade de armazenamento de água, e ainda favorecer a microfauna benéfica do solo, ou seja, de modo geral o composto pode gerar benefícios nas características físicas, químicas e biológicas do solo, tornando o sistema sustentável (LIMA et al., 2010).

O experimento teve por objetivo avaliar o efeito de diferentes concentrações de casca de amendoim como cobertura vegetal no desenvolvimento de duas variedades de alface. Para a avaliação dos dados foi utilizado o programa Assistat para realização da análise estatística. Para análise de variância foi utilizado o teste F e Tukey (5\%) para comparação das médias.

\section{METODOLOGIA}

O experimento foi conduzido na área experimental da Fatec (Faculdade de Tecnologia de Presidente Prudente - SP). O desenvolvimento do experimento, foi realizado durante o período de 29/09/2015 até 20/12/15.

O delineamento utilizado no experimento foi um fatorial $(1 \times 2 \times 4)$, sendo a cobertura utilizada a (casca de amendoim), duas variedades de alface lisa (Babá de verão) e crespa (Vera) e quatro concentrações de cobertura (testemunha "sem aplicação", 30 litros, 60 litros, 90 litros casca de amendoim).

Para cada tratamento foi utilizado um bloco (canteiro) a partir das medidas $(1,2 \mathrm{~m}$ de largura $\times 3 \mathrm{~m}$ de comprimento) totalizando 3,6 $\mathrm{m}^{2}$. Não houve incorporação de nenhum tipo de adubação no preparo dos canteiros, sendo o desenvolvimento das plantas realizado a partir apenas dos nutrientes disponíveis no solo.

No dia 10/10/2015, foram distribuídas as concentrações de cobertura vegetal no canteiro (casca de amendoim) e 18 dias depois foram transplantadas as mudas de alface oriundas de um viveiro situado no município de Álvares Machado - SP.

As plantas foram irrigadas diariamente em três períodos distintos ( 9 horas, 13 horas e 16 horas) através de aspersores do tipo P4 da marca Agrojet, com características de irrigar provocando uma precipitação suave, uniformemente distribuída, molhando as plantas sem provocar erosão no solo, não respingando terra para as mesmas e sem provocar injúrias nas folhas.

Após 50 dias da realização do transplantio das mudas foram realizadas as análises para avaliação do desempenho agronômico da alface, no qual foram avaliados os seguintes parâmetros: massa fresca, número de folhas, diâmetro e altura da planta.

Todos os dados foram submetidos à análise de variância (ANOVA, $p<0,05$ ) e ao teste de comparação de médias Tukey $(p<0,05)$, segundo Silva (2011). 


\section{RESULTADOS}

Tabela 01. Resultados de análises estatísticas das variáveis analisadas no experimento (Massa Fresca da Parte Aérea, Número de Folhas, Diâmetro da Parte Aérea e Altura da Planta) em relação as diferentes concentrações em volume de cobertura vegetal (casca de amendoim) utilizadas como tratamentos.

\begin{tabular}{ccccc}
\hline COBERTURA & MASSA FRESCA $(\mathrm{g})$ & No FOLHAS & DIÂMETRO $(\mathrm{cm})$ & ALTURA (cm) \\
\hline Testemunha & $160,03 \mathrm{~b}$ & $31,78 \mathrm{~b}$ & $41,27 \mathrm{a}$ & $16,89 \mathrm{a}$ \\
$30 \mathrm{I}$ & $237,83 \mathrm{a}$ & $44,28 \mathrm{a}$ & $45,88 \mathrm{a}$ & $17,78 \mathrm{a}$ \\
$60 \mathrm{I}$ & $70,72 \mathrm{c}$ & $26,17 \mathrm{~b}$ & $27,31 \mathrm{~b}$ & $13,14 \mathrm{~b}$ \\
$90 \mathrm{I}$ & $72,63 \mathrm{c}$ & $27,28 \mathrm{~b}$ & $27,46 \mathrm{~b}$ & $13,76 \mathrm{~b}$ \\
\hline CV (\%) & 46,25 & 39,42 & 33,46 & 22,43 \\
\hline
\end{tabular}

Médias seguidas por letras iguais na coluna não diferem entre si pelo teste de Tukey a 5\%.

Tabela 02. Resultados de análises estatísticas das variáveis analisadas no experimento (Massa Fresca da Parte Aérea, Número de Folhas, Diâmetro da Parte Aérea e Altura da Planta) em função da variedade lisa e crespa.

\begin{tabular}{ccccc}
\hline VARIEDADE & MASSA FRESCA $(\mathrm{g})$ & № FOLHAS & DIÂMETRO $(\mathrm{cm})$ & ALTURA (cm) \\
\hline LISA & $208,65 \mathrm{a}$ & $47,03 \mathrm{a}$ & $41,84 \mathrm{a}$ & $17,62 \mathrm{a}$ \\
CRESPA & $61,96 \mathrm{~b}$ & $17,72 \mathrm{~b}$ & $29,12 \mathrm{~b}$ & $13,16 \mathrm{~b}$ \\
\hline CV $(\%)$ & 46,25 & 39,42 & 33,46 & 22,43 \\
\hline
\end{tabular}

Médias seguidas por letras iguais na coluna não diferem entre si pelo teste de Tukey a 5\%.

\section{DISCUSSÃO}

Através dos resultados obtidos na tabela 01 , observa-se que grandes volumes de casca de amendoim como fonte de cobertura vegetal (60 e 90 litros por parcela) obtiveram menores respostas de componentes agronômicos avaliadas no experimento, com resultados inferiores até mesmo aos encontrados no tratamento testemunha (sem adição de cobertura vegetal), resultados esses com ênfase principalmente na produção de massa fresca da alface, fator esse essencial para comercialização do produto final. Já o tratamento com 30 litros por parcela de cobertura vegetal obteve os resultados mais significativos em relação aos componentes avaliados (massa fresca e número de folhas) quando comparado com os demais tratamentos utilizados no experimento. Para as variáveis (diâmetro e altura) os resultados obtidos no tratamento com 30 litros de cobertura foi estatisticamente igual ao tratamento testemunha. Dessa forma o tratamento com 30 litros é aquele que melhor se ajusta para um equilíbrio da produção de alface. Resultados similares a esses pode ser encontrado no trabalho de Adetunji (1994), quando estudando a resposta de cebola à cobertura do solo com casca de amendoim, observou que a cobertura do solo aumentou significativamente o crescimento vegetativo e a produção de bulbos de cebola.

$\mathrm{Na}$ tabela 02, temos os resultados dos componentes agronômicos (variáveis) em função das variedades lisa e crespa utilizadas no experimento. A variedade lisa obteve um melhor desenvolvimento com a adição da cobertura vegetal, sendo os seus resultados superiores em todos os componentes de produção quando comparado com a variedade crespa.

\section{CONCLUSÃO}

O uso de 30 litros de casca de amendoim como fonte de cobertura vegetal promoveu o melhor desenvolvimento da alface.

A alface lisa é a que melhor se desenvolveu no experimento com o auxílio da casca de amendoim como fonte de cobertura vegetal. 


\section{REFERENCIAS}

ADETUNJI IA. 1994. Response of onion to solarization and organic mulching in semi-arid tropics. Scientia Horticulturae 60: 161-166.

BIZARI, D. R.; MATSURA, E. E.; ROQUE, M. W.; SOUZA, A. L. de. Consumo de água e produção de grãos do feijoeiro irrigado em sistemas plantio direto e convencional. Ciência Rural, v. 39, n. 7, p. 2073-2079, out, 2009.

CADAVID LF; EL-SHARKAWY MA; ACOSTA A; SÁNCHEZ T. 1998. Long-term effects of mulch, fertilization and tillage on cassava growth in sandy soils in Northern Colombia. Field Crops Research 57: 45-56.

DIAS, P. S. Desempenho dos carvões obtidos a partir das biomassas caroço de piquí e da casca do cupuaçú em processos de adsorção de azul de metileno em meio aquoso. 2013 43p. Dissertação (Mestrado) - Universidade Estadual do Sudoeste da Bahia. Itapetinga, BA.

FELTRIN, A.L.; CECílIO FILHO, A.B.; BRANCO, R.B.F.; BARBOSA, J.C.; SALATIEL, L.T. Produção de alface-americana em solo e em hidropônica, no inverno e verão, em Jaboticabal-SP. Revista Brasileira de Engenharia Agrícola e Ambiental, Campina Grande, v.9, n.4, p.505-509, 2005.

FILGUEIRA, F. A. R. Novo manual de olericultura: agrotecnologia moderna na produção e comercialização de hortaliças. 2aㅡ. ed., UFV, 2003.

LOCK, K.; POMERLEAU, J.; CAUSER, L.; ALTMANN, D.R.; MCKEE, M. The global burden of disease attributable to low consumption of fruit and vegetables: implications for the global strategy on diet. Bulletin of the word health organization. February 2005, 83 páginas.

LIMA, T.M.; ASSUNÇÃO, H.F.; NAVARI, J.; LEITE, E.S.; MARTIM, A. Análise qualitativa das cascas de amendoim: uma alternativa de uso como fertilizantes orgânico. Cadernos de Agroecologia, vol5 N. 1. MS: UFG, 2010. 2 p. (Texto acadêmico).

MACLEAN RH; LITSINGER JA; MOODY K; WATSON AK; LIBETARIO EM. 2003. Impact of Gliricidia sepium and Cassia spectabilis hedgerows on weeds and insect pests of upland rice. Agriculture, Ecosystems and Environment 94: 275-288.

MOMENTÉ, V.G.; BARRETO, H.G.; SILVEIRA, M.A.; SANTANA, W.R.; TAVARES, I.B.; SOUZA, R.C.; ANDRE, C.M.G. Avaliação de linhagens F8 DE alface ao pendoamento precoce sob condições de temperaturas elevadas de Palmas-TO. In: CONGRESSO BRASILEIRO DE OLERICULTURA, 47. Resumos... Porto Seguro: ABH, 2007. (CD-ROM).

MONTEZANO, E. M.; PEIL, R. M. N. Sistemas de consórcio na produção de hortaliças. R. Bras. Agrociência, Pelotas, v. 12, n. 2, p. 129 -132, abr-jun, 2006.

OLIVEIRA, N. G.; DE-POLLI, H.; ALMEIDA, D. L; GUERRA, J. G. M. Plantio direto de Alface Adubada com "Cama" de Aviário Sobre Coberturas Vivas de Grama e Amendoim Forrageiro. Horticultura Brasileira, Brasília, v. 24, p. 112-117, 2006. 
ROSOLEM, C. A.; CALONEGO, J. C.; FOLONI, J. S. S. Lixiviação de potássio da palha de espécies de cobertura de solo de acordo com a quantidade de chuva aplicada. Revista Brasileira de Ciência do Solo, Viçosa, v. 27, n. 2, p. 355-362, 2003.

SALA, F.C.; COSTA, C.P.; TEIXEIRA, L.D.; FABRI, E.G.; BLAT, S.F. Reação de cultivares de alface a Thielaviopsisbasicola. Horticultura Brasileira, Brasília, v. 26, n. 3, 2008.

SANTIAGO, B. H.S.; FRANÇA G.H.C.; FERNADES R.; SELVAM, P. V. P. Estudo de viabilidade tecnoeconomica preliminar para produção de carvão ativado no Brasil a partir dos resíduos do coco: estudo comparativo de cenários de produção. Revista Analítica Universidade Federal do Rio Grande Norte - UFRN, Núcleo de Tecnologia - NT. n¹. 2005.

SILVA, F. de A. S. Assistat. Versão 7.6 beta (2011). Disponível em http://www.assistat.com/indexp.html.

SOUZA, J. L.; RESENDE, P. Manual de horticultura orgânica. Viçosa: Aprenda Fácil, 2003. 564 p.

SOUZA, P.A.; NEGREIROS, M.Z.; MENEZES, J.B.; BEZERRA NETO, F.; SOUZA, G.L.F.M.; CARNEIRO, C.R; QUEIROGA, R.C.F. Características químicas de alface cultivada sob efeito residual da adubação com composto orgânico. Horticultura Brasileira, Brasília, v. 23, n.3, p. 754-757, jul set.2005.

VAN DUYN, M.A.S.; PIVONKA, E. Overview of the health benefi ts of fruit and vegetable consumption for the dietetics professional: selected literature. Journal of The American Dietetic Association, 2000. v. 100, n.12, 10 p. 